\title{
Methodologies for the evaluation of seismic vulnerability of complex masonry buildings: case histories in the historic centre of Sulmona
}

\author{
L. Binda, A. Anzani \& G. Cardani \\ D.I.S - Politecnico di Milano, Italy
}

\begin{abstract}
This paper describes a procedure, addressed to an articulated knowledge of the material, of the morphology and of the constructive aspects of the masonry structures, of the mechanical behaviour and of the possible failure mechanisms of complex buildings in Sulmona (AQ), an important historic centre in Central Italy. It is an area of great interest, not only considering its seismic history, but also because of the characteristics of its prestigious buildings, mainly made of multiple leaf stone masonry.

The understanding of the historical buildings has made use of a direct survey of the constructions (based on a geometrical survey, on a survey of the materials and of their state of damage), of indirect information deduced by documentary sources, and of data collected through in-situ non destructive or minor destructive testing and laboratory investigation for a chemical, physical and mechanical characterisation of the masonry and of its components.

Record templates and forms, some of them purposely set up, have been adopted and collected into a database for the damage and masonry quality assessment and the evaluation of the future vulnerability of the buildings to in-plane and out-of-plane actions according to damage abacuses previously produced.
\end{abstract}

Keywords: ND evaluation, multiple leaf masonry, cross section morphology, historical complex buildings.

\section{Introduction}

The analysis suggested by the present Italian Seismic Code (OPCM 3274/2003 [1] and subsequent modifications) for the knowledge of existing buildings is 
considered excessively heavy for intervention on single buildings, especially if it rises within an aggregate, a very common condition in historical centres. A compromise is therefore necessary between what it is reasonably demanded to a designer and what is essential from an exhaustive knowledge point of view. The problem can be faced by a method that can be easily applied through record templates and forms and allows the strength and vulnerability characteristics of a building to be individuated, which are crucial towards the structural seismic response.

A multi-level procedure has been set up and applied here to study complex buildings in the historical centre of Sulmona (AQ). The investigation method adopted by the Authors since the beginning of the '90s (Binda et al. [2]) is based on the principle that knowledge is fundamental for the choice of suitable techniques and materials aimed to the preservation and damage prevention of the cultural heritage.

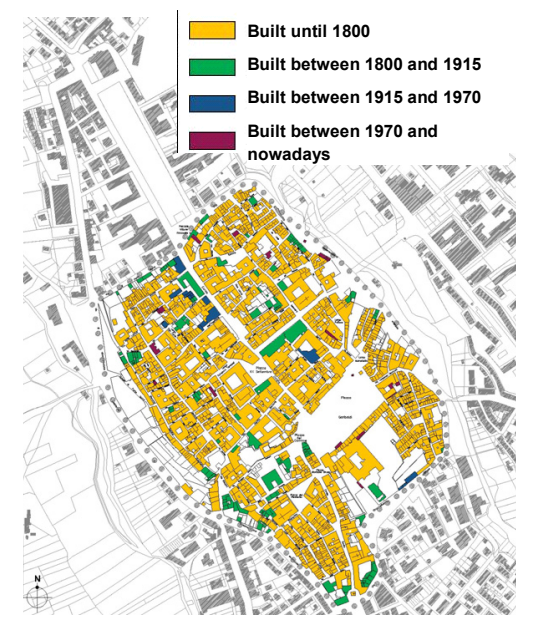

Figure 1: Historic evolution of the historic centre of Sulmona.

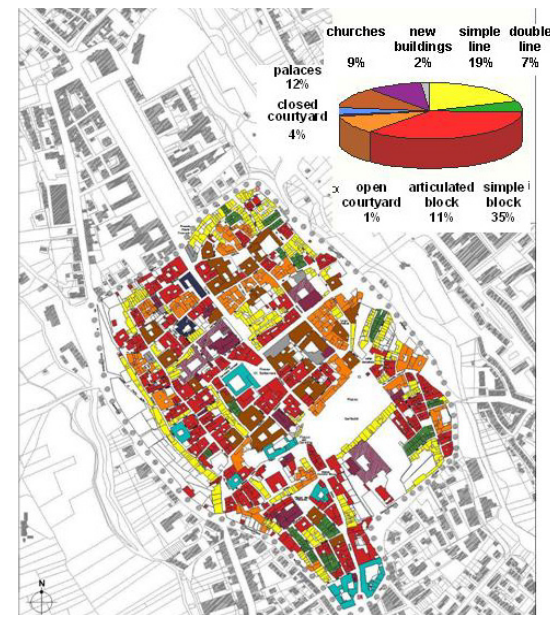

Figure 2: Distribution of building typologies in the centre of Sulmona.

This procedure has been well calibrated in different on site investigations on historic masonry buildings in the Umbria region after the earthquake of 1997 (Anzani et al. [3]), in the Liguria region (Anzani et al. [4]) hit by earthquakes in the $19^{\text {th }}$ century, in the area of Garda Lake involved in the earthquake of 2004 (Anzani et al. [5]; Cardani et al. [6]). The earthquake that struck Umbria and Marche regions in '97 gave the occasion to learn that the lack of knowledge on the material and structural behaviour of the existing buildings was, and still is, the main cause of inappropriate choices of the intervention techniques. The problem of repair and retrofitting should be approached in a multidisciplinary way, considering different complementary aspects including: historical evolution of the buildings, geometry and crack pattern, material characteristics, technology 
of construction, possible failure mechanisms, etc (Penazzi et al. [7]). To this respect, the collaboration between architects/"restorators", historians, structural engineers is particularly important. All the collected complementary data will allow an interpretation of the structural response which takes account of the examined masonry and building typology, leading to evaluate the seismic vulnerability and to define reliable retrofitting procedures of stone-masonry buildings.

\section{Study of the historic centre of Sulmona}

The first phase of the research presented here consisted of a study of the historical centre of Sulmona aimed to understanding the rules of the formation and growing of the built types, starting from the first construction until the fusion and complex additions of new bodies. The city was founded by the Romans and had a subsequent development in medieval time. In fig. 1 the more recent evolution is shown, where it appears that the main part of the edification has been mostly carried out before 1800 . After collecting historical information on the evolution of the ancient city centre, the elements having structural relevance are analysed.

Diffuse architecture, often poorly constructed, is mainly composed of stonework buildings with timber roofs and floors. In spite of the use of apparently similar material and construction techniques, building characteristics vary according to their typology - from isolated to arrayed buildings - and to their location - from flat to steep mountain sites. This variety is directly connected to the orographical profile of the site and also to the common seismic history.

The recognition of the building typologies and of the characteristic constructive elements is a fundamental aspect aimed to their typo-morphological classification and to the creation of a catalogue of the constructive elements characteristic of the local architecture.

The importance of recognizing different building typologies, in view of the definition of their seismic vulnerability, depends on the correspondence between construction typologies and mechanisms of damage. Considering complex cases as for the geometry and original destination, it has to be pointed out that any typology, for instance palaces, religious buildings, towers, castles, fortifications, churches, etc., display specific problems, also connected to the function of the building itself. Such differences, that have influenced the original constructive solutions and the wall masonry quality, similarly will influence the safety assessment and the techniques of intervention. Therefore, for any typology, the matter should be to individuate and manage specific level of investigation, modelling, verification and specific repair techniques, satisfying also the function requirements.

In fig. 2 the location of buildings erected in $20^{\text {th }}$ century, together with that of historical building typologies have been mapped, consisting of simple and double lines, simple and articulated blocks, open and closed courtyards, palaces and churches. It appears that the area of the city centre is mainly occupied by 
articulated blocks and also that many churches are present. Most of the buildings denominated "palaces" resulted from the evolution and the fusion of different residential units initially conformed as simple or double lines, mainly during the XVI century, improved through inner courtyards and decorative apparatus.

Subsequently, a template aimed to the "Masonry quality evaluation" was adopted and applied to selected buildings characterized by facades with no plaster finishes, therefore having their stonework masonry texture available to visual inspection (figs. 3 and 4). The prediction of the seismic vulnerability of stonework masonry, and particularly of the multiple wythe stonework, can only be performed provided the intrinsic characteristics of the masonry have been accurately detected. The behaviour of masonry highly depends on the construction technique and this is shown from the section layout. In fact, the outer face frequently does not reveal how the masonry section is built since apparently similar facing textures (e.g. regular bonding) may correspond to different types of sections, as one or multiple wythes (Hendry [8]). A systematic study of the mechanical behaviour of stonework masonry begins from an extensive investigation taking into account the different layers constituting the wall and the kind of constraints which may or may not exist between the layers themselves. From the analysis of this information, constitutive laws for modelling the masonry behaviour and for designing possible repair interventions (e.g. injection of grout) can be selected. Input data for the structural analysis with numerical methods are the section survey and the type of connection between the layers. These features can also be taken into account when modelling the inplane or out of plane failure mechanisms.

Most of the historical buildings in Sulmona turn out to be characterized by three leaf stonework masonry (fig. 5). Considering the masonry textures on the wall facades, they mainly consist of disordered rubble stone rubble (according to
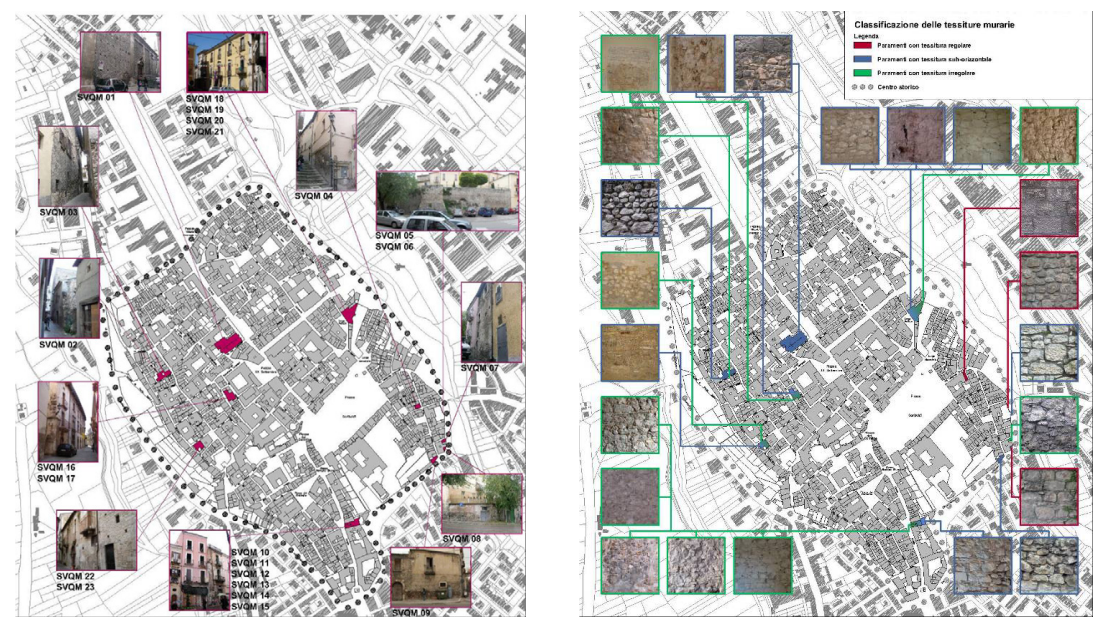

Figure 3: Recognition of building facades without plaster for masonry qualification.

Figure 4: Studied masonry typologies. 
table 11.D.1 of the Italian Seismic Code 3431/2005 [9]), always of calcareous nature, with friable mortar. The observed textures are generally made of irregular and sub-horizontal courses, in few cases of regular ones, and with unfinished or partially finished stone blocks. The stone interlocking on the outer face is generally low or very low, in few cases medium. In general the masonry quality, evaluated by visual inspection, turns out to be scarce. On some of these buildings, also a second template aimed to the "Typological and seismic damage survey of buildings" and the evaluation of their vulnerability was applied. Both Templates had been set up within the framework of the Italian Network of University Laboratory of Seismic Engineering (ReLUIS).
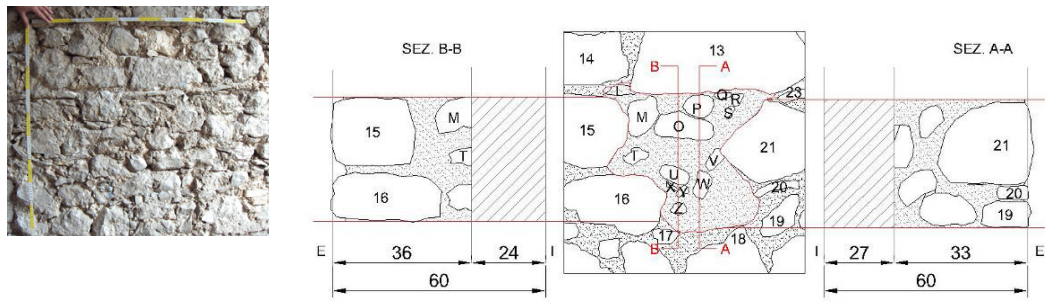

Figure 5: $\quad$ Three-leaf masonry section on block 39 in Ovidio Street.

\section{Direct investigation on selected case studies}

Significant aggregates were identified (painted red in fig. 3 and blue in fig. 4) and subjected to a systematic investigation which included the following phases: (i) geometrical survey of the building and of its crack pattern, (ii) interpretation of the crack pattern and definition of the damage or collapse mechanisms affecting each building, (iii) detection of the connections between walls and between roofs and vaults to walls, (iv) non destructive evaluation of damage, (v) survey of the masonry texture and of the morphology of the wall sections, (vi) on site characterisation of the masonry walls through sonic and flat-jack tests, (vii) sampling and laboratory characterisation of mortars, plasters and stones through chemical, physical and mechanical tests.

Aggregates of historical buildings have generally been subjected to the addition of several volumes in different times, and the possible discontinuities between the different volumes could affect the overall seismic behaviour. In fig. 6 block 69 in Acuti Street is shown as an example. Its volume was apparently rather simple when looked from the outside, whereas required to be subdivided into three macro-elements once surveyed in more detail (figs. 7-9). For a reliable interpretation of the signs of damage, the preliminary in-situ survey, useful to obtain details on the geometry of the structures, identifying irregularities like vertical deviations, rotations, etc. needed complementary indication coming from the investigation of the historical evolution of the structure in its complexity (fig. 10). 
On the chosen case studies, significant walls were recognized for a complete characterization of the masonry where the following tests were systematically carried out: (i) sonic tests by transparency on a grid of $75 \times 75 \mathrm{~cm}$ for measurement of the sonic velocity, (ii) single and double flat-jack tests for measurement of the state of stress, the modulus of elasticity and the coefficient of lateral expansion, (iii) survey of the masonry morphology and material sampling for characterizing the mortar and stones chemical, physical and mechanical properties, (iv) repositioning of the stones in the wall.

In fig. 11 the results of sonic tests on a pillar rising at ground floor of block 69 are reported. It is interesting to observe the agreement between the distribution of sonic velocity, with higher values corresponding to the outer portions of the pillar and lower values at mid span, and the crack pattern, showing cracks running where the lower velocity has been recorded.

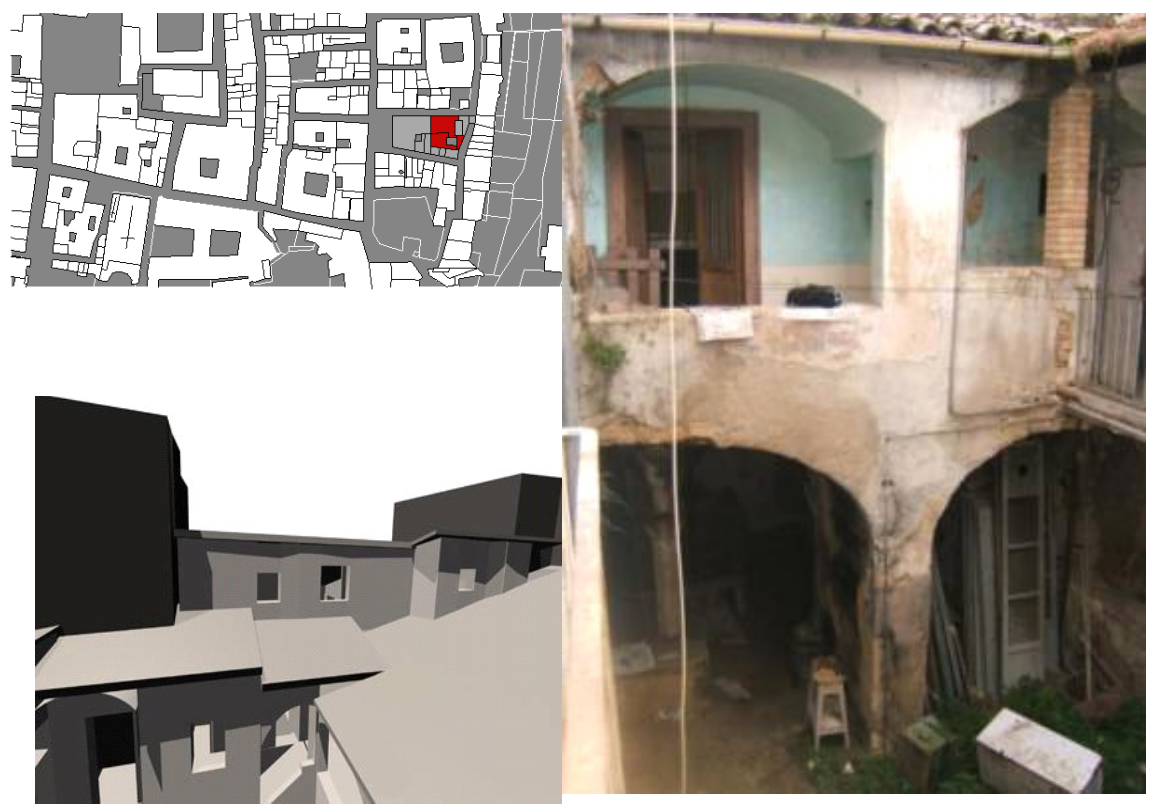

Figure 6: $\quad$ Location and views of block 69 in Acuti Street.

After in situ and laboratory characterization and a 3D evaluation of the crack pattern, the main weakness characteristics towards the building seismic response were singled out. In fig. 12 the presence of a standing out body and a room with the lack of the floor are indicated as an example.

Another case study is presented in fig. 13, where on the plan of the building aggregate different colours indicate two constructive phases and capital letters refer to the testing points. Corresponding to point A, where parts of the building erected in different years converge, the masonry inspection after plaster removal highlighted that stone interlocking was absent (fig. 14) and therefore that the two 
walls presented no connections. Results of sonic and flat jack characterization of a wall located in the more recent part of the complex are reported in figs. 15 and 16. The results of in situ testing gave a confirmation of what was observed by visual inspection. The masonry quality resulted generally scarce, characterized by low values of sonic velocity; in some cases flat jack tests encountered difficulties to be applied, and indicated very high values of both vertical and horizontal displacements.

The survey of the morphology of the wall cross section was aimed to understanding whether the masonry was made of one or more leaves and whether the leaves were connected in some way. It was carried out by drilling, taking off some stones in order to visually investigate the wall texture, sketch the inner aspect of the wall and sample stones and mortars for laboratory testing.

The mortars were submitted to chemical and physical analyses. The binder was separated from the aggregate by thermal attack and the grain size distribution was measured as shown in fig. 17. Since the aggregate was mainly calcareous, it was not possible to determine the binder/aggregate ratio

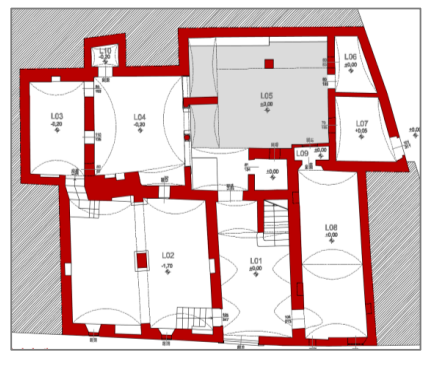

Figure 7: Ground floor of block 69.

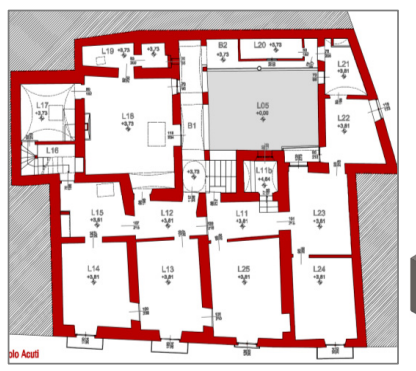

Figure 8
First floor of block 69.

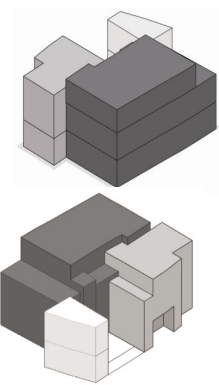

Figure 9: Macroelements.

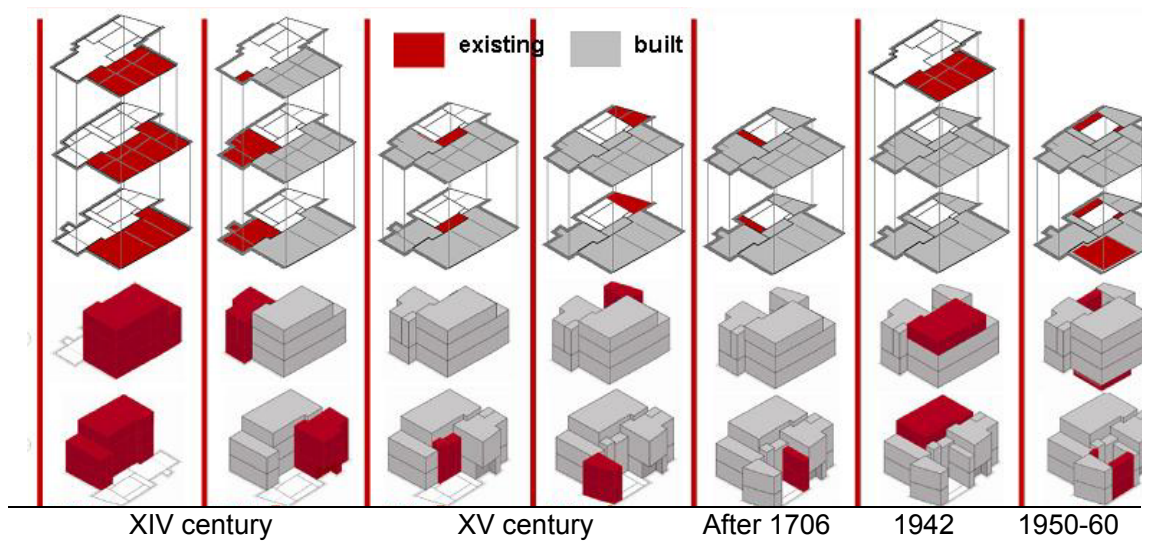

Figure 10: $\quad$ Historical evolution of block 69. 
chemically. Most of the mortars were similar, with the binder being hydrated lime. The stones belonged to several litho types but limestone was the most frequent one.

\section{Discussion of the results and conclusions}

The seismic vulnerability assessment of historical buildings should consist of an articulated procedure based on indirect and direct sources of information, leading to the identification of the most typical failure mechanisms activated by the earthquake and allowing for appropriate analytical models. The paper describes the application of a multi-disciplinary procedure, addressed to an articulated knowledge of morphological and constructive aspects of the masonry elements of stone-masonry buildings in the historical centre of Sulmona. The results have been used for the application of the automatic procedure Vulnus vers. 4.0 (Binda et al. [10]) to obtain a global seismic vulnerability assessment, based on a probabilistic evaluation of the percentage of structural units exceeding a fixed ratio between average response acceleration and gravity acceleration.

According to the experimental results, indicating a low quality of the masonry constituting the analyzed case study, it turned out that the structural units in the historical centre of Sulmona, if subjected to seismic action, show a better in plane than out of plane response, demonstrating a very high vulnerability.

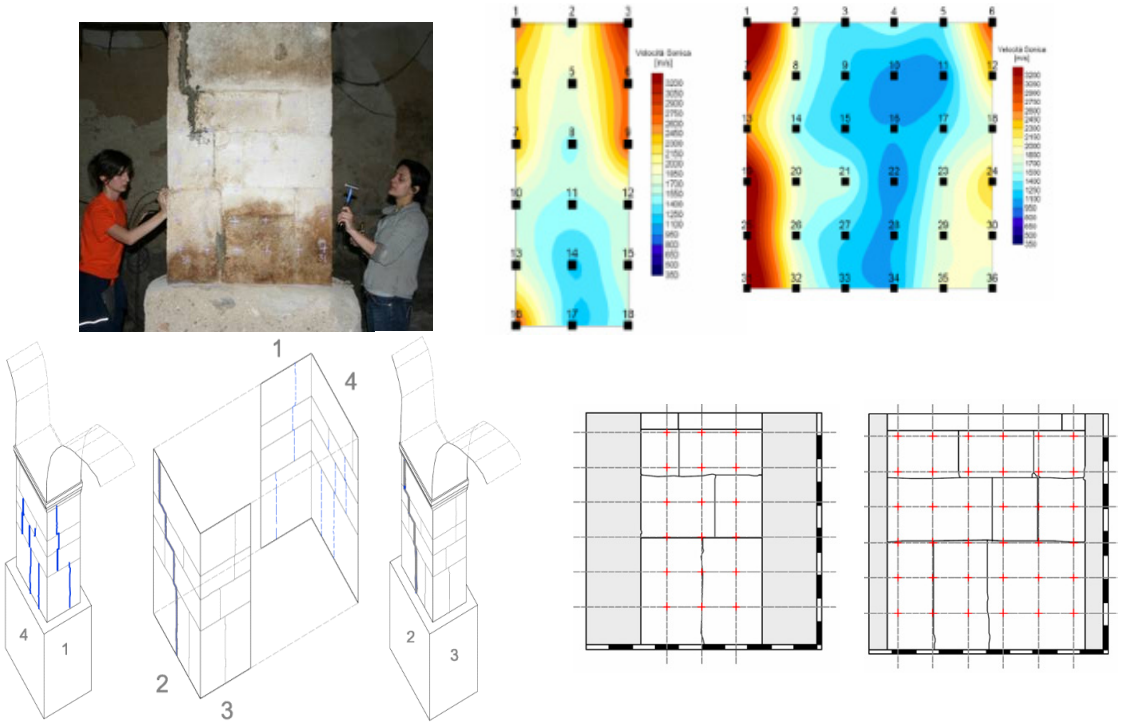

Figure 11: Sonic characterization and study of the crack pattern of a pillar at ground floor of block 69 . 


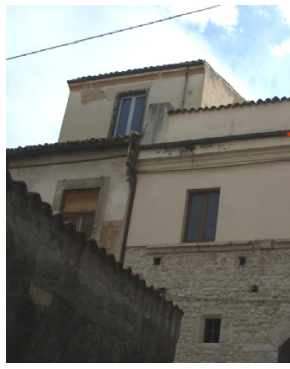

a)

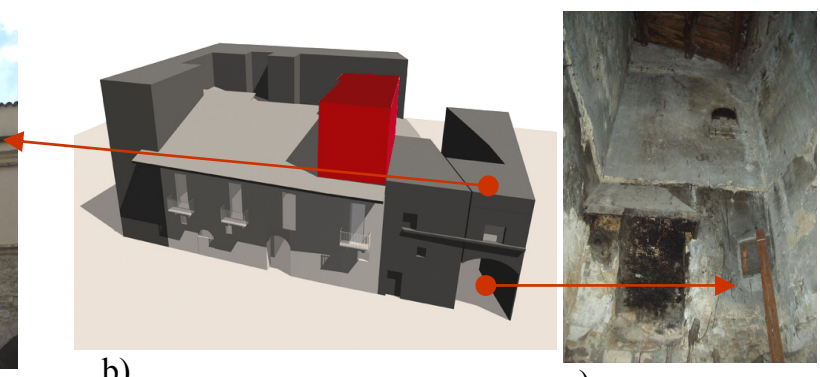

b)

c)

Figure 12: Weaknesses in block 69: standing out body (a); lack of floor (c).

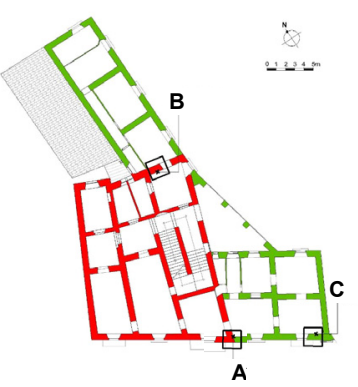

Figure 13: Sardi Palace in Palizze Street: - original parts; - parts added in $19^{\text {th }}$ century.

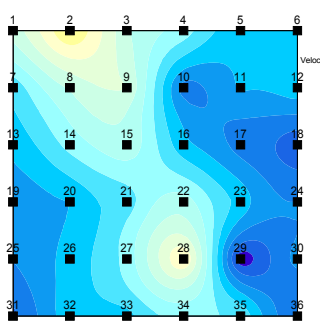

a)

average velocity 1016,3 $\mathrm{m} / \mathrm{s}$
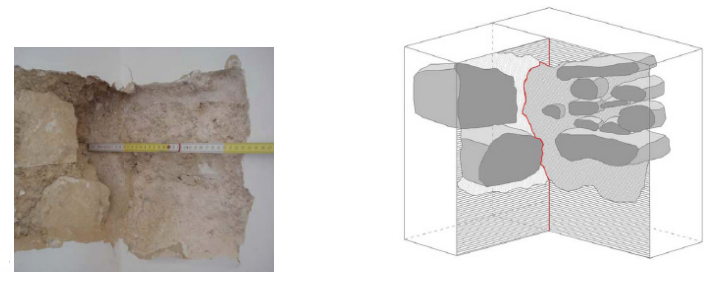

Figure 14: Study of wall interlocking on corner A of figure 13.

Figure 15: Sonic (a) and double flat jack (c) characterization of wall C (b) of figure 13.

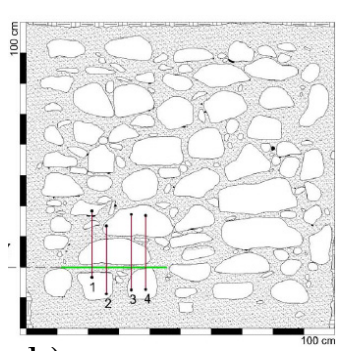

b)

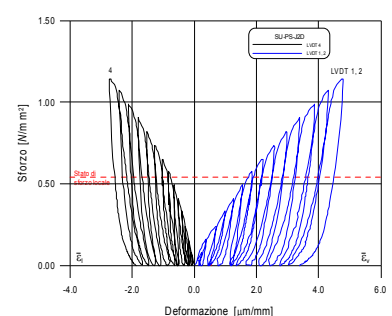

c) average $E 1737\left(\mathrm{~N} / \mathrm{mm}^{2}\right.$ 


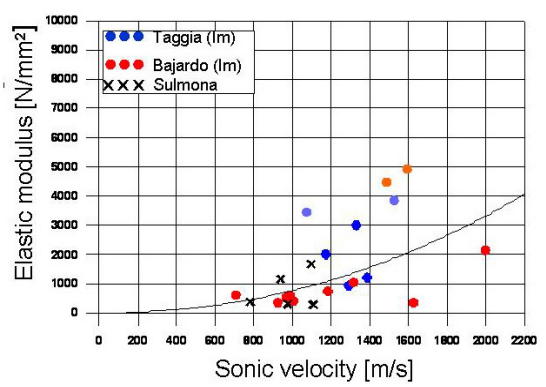

Figure 16: Relationship between E measured through double flat jack test and sonic velocity.

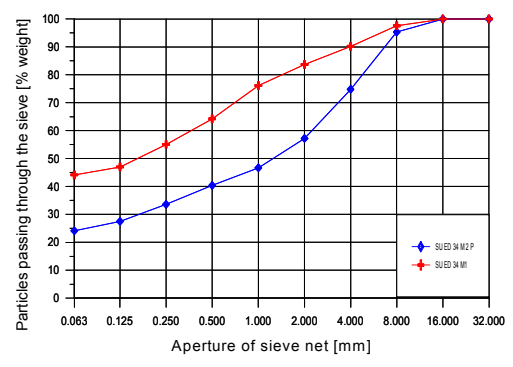

Figure 17: Grain size distribution of mortar aggregates.

\section{Acknowledgements}

The authors wish to thank eng. A. Martinelli of C.N.R. I.T.C. L'Aquila and arch. B. Matticoli. The research was co-financed by the National projects RELUIS. M. Antico, M. Cucchi, M. Iscandri, A. Colombo are gratefully acknowledged for their technical support; many thanks are also due to the students: C. Ferrario, S. Francotti, G. Germano, P. Lombardo, L. Restelli, D. Rossini and V. Sgobba.

\section{References}

[1] OPCM 3274/2003.

[2] Binda L., Baronio G., Gambarotta L., Lagomarsino S., Modena C., Masonry constructions in seismic areas of central Italy: a multi-level approach to conservation, 8NAMC (North American Masonry Conf.), Austin, USA, pp. 44-55, CD-ROM, 1999.

[3] Anzani A., Baila A., Penazzi D., Binda L., 2004, Vulnerability study in seismic areas: the role of on-site and archives investigation, IV Int. Seminar Structural Analysis of Historical Constructions, Padova 10-12/11/2004, Vol. 2, pp. 1051-1059, ISBN 0415363799.

[4] Anzani A., Baila A., Penazzi D., Binda L., Vulnerability study in seismic areas: the role of on-site and archives investigation, IV Int. Seminar "Structural Analysis of Historical Constructions", Padova 10-12/11/2004, Vol. 2, pp. 1051-1059, ISBN 04 15363799, 2004

[5] Anzani A., Binda L., Cantini L. Cardani G., Saisi A., Tedeschi C., On site and laboratory investigation to assess material and structural damage on some churches hit by an earthquake, XII Conv. Naz. L'Ingegneria Sismica, ANIDIS 2007, Pisa 10-14/6/2007, DVD, Edizioni Plus, Pisa, pp. 1-10, 2007. 
[6] Cardani G., Anzani A, Binda L., Saisi A., On site structural assessment of Churches in Stone work damaged by the Earthquake, 2nd Canadian Conference on Effective Design of Structures, McMaster University, Hamilton, Ontario, Canada, 20-23/05/2008, pp. 1-10, CD-ROM ISBN: 09738035-3-2.

[7] Penazzi D., Valluzzi M.R., Cardani G., Binda L., Baronio G., Modena C., Behaviour of historic masonry buildings in seismic areas: lessons learned from the Umbria-Marche earthquake, 12 IBMaC, Madrid, 2000.

[8] W. Hendry, Aspects of stability and strength of stone masonry structures, Third International Masonry Conference, Proceedings of the British Masonry Society, No. 6, March, 1994.

[9] OPCM 3431/2005

[10] Binda L., Cardani C., Saisi A. Valluzzi M.R., Munari M., Modena C., Multilevel approach to the vulnerability analysis of historic buildings in seismic areas, Part 1: Detection of parameters for vulnerability analysis through on site and laboratory investigations, IJRBM Journal of Restoration Building and Monuments, ISBN: 1864-7251, Vol. 13, N. 6, pp. 413-426, 2007. 